LICENÇA CC BY:

Artigo distribuído sob os termos

Creative Commons, permite uso e distribuição irrestrita em qualquer meio desde que o autor credite a fonte original.

\author{
EL CUERPO HABLA: INVESTIGACIÓN- \\ CREACIÓN \\ EL CUERPO HABLA: RESEARCH-CREATION \\ EL CUERPO HABLA: PESQUISA-CRIAÇÃO
}

Angela María Chaverra Brand ${ }^{1}$

Colômbia.

Artículo recibido en: 03/04/2020

Aceptado en: 04/11/2020

Resumen: La investigación-creación que presentamos, aborda a partir de un acto de fabulación con la comunidad, a través de un dispositivo como la performance, el despliegue de un tema controversial en la historia del arte de occidente y es la propuesta de entender el arte como acontecimiento social y político, más que como obra de arte terminada; allí se presentan como lo propone Guattari, tres aspectos fundamentales: la ética, la estética y las producciones de subjetividad, mediante el levantamiento de una cartografía social como una estrategia artístico-política en la que interviene la comunidad en el rol de intercesor del proceso, lo que permite inferir en las dinámicas pedagógicas, sociales, políticas, creativas de la sociedad y hacer de la vida una obra de arte, como respuesta al malestar contemporáneo.

Palabras-clave: Acontecimiento; Subjetivación; Cartografía.

Abstract: The research-creation that we present here addresses, based on an act of fabulation with the community, through performance as a device, the unfolding of a controversial subject in the history of western art; the proposal is to understand art as a social and political event, rather than as a finished work. This is shown in three fundamental aspects proposed by Guattari: ethics, aesthetics and the productions of subjectivity, through the raising of a social cartography as an artistic-political strategy in which the community intervenes, in the role of intercessor of the process, allowing the pedagogical, social, political and creative dynamics of society to be inferred, and making life a work of art, in response to the contemporary malaise.

Keywords: Event; Subjectivation; Cartography.

Resumo: A pesquisa-criação que apresentamos aborda, a partir de um ato de fabulação com a comunidade, por meio da performance como um dispositivo, o desdobrar de um tema controverso na história da arte ocidental; a proposta está em compreender a arte como acontecimento social e político, mais do que obra de arte finalizada. Isto se mostra em três aspectos fundamentais propostos por Guattari: a ética, a estética e as produções de subjetividade, por meio do levantamento de uma cartografia social como uma estratégia artístico-política na qual a comunidade intervém no 
papel de intercessora do processo, o que permite inferir nas dinâmicas pedagógicas, sociais, políticas e criativas da sociedade e fazer da vida uma obra de arte, como resposta ao mal-estar contemporâneo.

Palavras-chave: Acontecimento; Subjetivação; Cartografia.

(...) Un mapa es siempre asunto de performance (...) el deseo siempre se produce y se mueve rizomáticamente (...) [es] importante la otra operación, inversa pero no simétrica: volver a conectar los calcos con el mapa, relacionar las raíces o los árboles con un rizoma (DELEUZE; GUATTARI, 2002, p. 17).

Dice Guattari (2015), que la tarea de la ecosofía mental es dar lugar a una articulación ético-estética que reinvente las relaciones sujeto-cuerpo-sensibilidad; la construcción de una estética de la existencia, que implica un proceso de singularización que se opone y resiste al sistema-estructura de la subjetividad producida por los sistemas de poder.

Así, desde esta invitación que hace Guattari, se generan una serie de procesos que tienen como fin la construcción de una ética del cuidado de sí, hacer de la vida una obra de arte y crear actos de fabulación como resistencia frente a un poder que quiere homogeneizar los cuerpos; resignificar el sentido de la colectividad a través de la producción de acontecimientos artísticos y entender la singularidad y la diferencia en las dinámicas de subjetivación.

La pregunta que surge frente al proceso que se lleva desde hace muchos años, en el que se han expandido conceptos como: cuerpo, re-presentación, fabulación, resistencia, es ¿cómo posibilitar a través del acontecimiento artístico un entendimiento y transformación de las tensiones, los juegos, las relaciones sociales, las construcciones de subjetividades que se pliegan y despliegan para hacer frente a un malestar social? Esta pregunta nos enfrenta a un territorio que queremos explorar, en el que no se define un objeto de investigación clásico, sino que se propone desde una cartografía que nos permita entender la investigación como acción creadora, como levantamiento de una serie de elementos de orden heterogéneo que se entrecruzan y nos posibilita analizar en qué condiciones se da eso que hemos llamado acontecimiento artístico, y cómo estos tópicos se pueden configurar como un referente para la sociedad y para la academia que aporte a la reflexión sobre un arte contemporáneo ligado a la vida, a los procesos políticos, dado el impacto social que se ha tenido a través de las diferentes experiencias de ciudad en las que hemos actuado, en la que se privilegia un dispositivo como la performance.

La construcción de esta cartografía la retomamos desde la perspectiva de Guattari como el conjunto de planos de inmanencia de indagación social, política, estética y ética; esto nos permite configurar, desde una apuesta por el arte no instaurada como categoría de estudio o producto de una determinada área del saber moldeada por el proyecto de la modernidad, llámese historia del arte, filosofía del arte, estética entre otras, sino como un accionar constante, un acontecimiento en su propio devenir para saber qué efectos se producen dentro de una ventana de observación social. Dice Guattari que 
la singularización es una existencia en flujo, que se construye desterritorializándose en un nomadismo existencial. La ecosofía es una heterogénesis, una serie de procesos continuos de re-singularización, de experimentación (GUATTARI, 1996, p. 60).

Concluye además que sin los escenarios creativos permanentes para combatir la violencia, la sociedad corre un riesgo de cristalizar la muerte en lo real; concluimos que eso es lo que está pasando actualmente en Colombia y el mundo. Por ello la importancia de crear acontecimientos artísticos que más que "obras de arte" para la contemplación, produzcan efectos sociales en actos de vida y resistencia.

Y es en ese escenario político, en el cual el arte se configura como un lugar de resistencia, en el que hemos encontrado nuestro lugar de interés. La última experiencia del trabajo con el Partido de las Doñas, una comunidad conformada en su mayoría por mujeres de la vereda Granizal de Bello y los barrios Pablo Escobar, Belén Altavista y El Popular de Medellín, que accionan como madrinas de la ciudad, para enfrentar la violencia de sus lugares, ha evidenciado cómo una acción performática posibilita reconocimientos del territorio, les permite sentirse parte de una construcción social. Dos gestos cotidianos: sembrar y tejer fueron acciones que les proporcionaron la fuerza para entenderse desde su particularidad, descubrir la potencia de su cuerpo y los lazos de solidaridad y de respeto que se cuecen en esos escenarios.

Es a partir del encuentro entre nosotros, el Partido de las Doñas y la comunidad que enfrentamos el sentido de la fabulación, de la llamada a un pueblo que falta, de los actos de habla que aparecen en el proceso, de la relación del arte con un territorio, asuntos que implican para nosotros tejer y construir subjetividad porque allí el arte cobra un sentido político, ético, estético, para atender a eso que Guattari (2015) ha llamado la estética de la existencia o lo que Foucault llama hacer de la vida una obra de arte.

Nuestras acciones se proponen como acontecimientos artísticos para crear resonancias, congregar comunidades e invitar a movilizar fuerzas conjuntas como acto de resistencia. Seguimos insistiendo en que las prácticas artísticas trascienden el lugar de la contemplación clásica del Arte y se vuelcan hacia la comunidad en general para impactar una sociedad y generar grandes o pequeñas fisuras que a modo de rizoma se extienden, resonando y generando pliegues. Es por eso que nos asimos a la trayectoria hasta el momento recorrida y le apostamos a una propuesta de creación abierta, móvil, en constante cambio que se nutre con los procesos de investigación. Desde inicios del siglo $\mathrm{XX}$, pero muy particularmente en esta contemporaneidad, las condiciones institucionales, filosóficas y estéticas que circunscribían el arte al terreno de lo bello, lo sublime y lo contemplativo se han transformado de manera tal, que el horizonte hermenéutico del mismo como práctica ha rebasado los museos y las galerías, para abrirse a diferentes escenarios en los que se encuentran experiencias en las cuales pueden rastrearse otros sentidos, motivaciones, dinámicas y conceptos que se insertan en redes polisémicas, en intenciones y fuerzas en tensión que conjugan aspectos sociales, políticos y éticos, lo que en otras palabras, podría denominarse como un giro epistemológico pero también ontológico frente a la concepción del arte como una categoría nominal desde la modernidad. 
Uno de los escenarios en los que se despliega dicho horizonte, es la indagación por los acontecimientos artísticos o el considerar al arte como un acontecimiento que resuena con otras inquietudes y propósitos situados en un contexto social, diferentes a los definidos por la estética tradicional. En este sentido, se genera un campo de exploración que parte de una crítica a los cimientos modernos del arte, entendido como categoría unidireccional, para luego localizar otras prácticas estéticas como la performance, las acciones de la carne, que nos permitan construir su sentido desde las condiciones que nos presenta la contemporaneidad; por ejemplo, la instauración de lógicas de saber y poder neoliberales en las funciones del Estado, la expansión de la guerra como estrategia económica de los países "desarrollados" para apropiarse de los recursos de los países "subdesarrollados", la oleada de problemas medioambientales derivados de la explotación desmedida de la naturaleza, las violencias generadas por las opciones éticas, estéticas, sexuales diversas; pero también las estrategias de vida locales que surgen en respuesta a las problemáticas globales, en las que el arte deviene, no un objeto u obra, sino un proceso, un llamado a un pueblo, un acontecimiento que busca revivir las potencias de vida en una comunidad.

En esta dirección se encamina el trabajo investigativo-creativo que presentamos: en la indagación y construcción de una práctica artística que se conecta con una pregunta de orden social y estética que es sumamente política y ética, razón por la cual nos interesa hablar del arte desde otros puntos de vista y para este caso, recurrimos a la relación teórica entre el acontecimiento, la subjetivación y la cartografía, conceptos que nos permiten construir una red de sentido acerca del arte en la contemporaneidad, y de las prácticas artísticas como actos y procesos de fabulación.

Haciendo eco de los conceptos de Guattari de la ecosofía, que atraviesan estratégicamente tres registros: medio ambiente, sociedad y producción de subjetividades, proponemos la creación de formas alternativas de habitar el mundo, la reconstrucción y regeneración de las relaciones sociales con miras a la configuración de prácticas micropolíticas y procesos de singularización cuyo efecto es la creación e invención de territorios existenciales inéditos que re-articulen armónicamente los tres registros ecosóficos (GUATTARI, 1996). Esto interroga la manera en que habitamos el planeta, la capacidad de enfrentarnos a los dispositivos de poder que modelan los cuerpos y las formas de "ser" de una comunidad. En este sentido para Guattari:

nuestra supervivencia en el planeta está amenazada no sólo por las degradaciones ambientales sino también por la degeneración del tejido de solidaridades sociales y de los modos de vida psíquicos que conviene literalmente reinventar (GUATARRI, 1996, p. 72).

Por ello relacionamos nuestro hacer con tres conceptos fundamentales que, han cruzado las diversas investigaciones-creaciones realizadas desde el 2006, para crear una mirada alternativa al arte en la contemporaneidad mucho más comprometida con los devenires sociales. Estos conceptos son: Acontecimiento, Subjetivación y Cartografía, los cuales se insertan perfectamente con los conceptos de fabulación, performance y acciones de la carne que se han trabajado anteriormente dentro de un marco de investigación-creación y una ruta cartográfica. 


\section{Arte y Acontecimiento}

Entendemos el acontecimiento como una acción transformadora de alta potencia en la que se cruzan vectores que crean multiplicidades y conexiones a manera de un collage, lo que permite describirlo desde un lenguaje artístico contemporáneo. Siguiendo a autores como Consuelo Pabón, Foucault, Deleuze, Guattari, Pardo y Ordoñez, concluimos que el acontecimiento se da en un espacio y en un tiempo que no son determinados, porque son no tiempos y no espacios, más bien pueden entenderse como un pasaje, un entretiempo que se superpone, en el cual se crea un sentido en un ahora presente y despliega un afecto que tiene una duración que puede ser efímera, aunque paradójicamente eterna.

Dicen los autores referidos que el acontecimiento nos convierte en videntes y ello permite cambiar la mirada pasiva por una creativa; es por eso que el arte difiere de otros lenguajes estéticos, porque se aleja de un espectáculo como tal en la medida en que nos invita a ser partícipes, a ser parte de ese pueblo que está por construirse. "Ustedes saben, falta el pueblo" dice Paul Klee (CHAVERRA, 2017, p. 46) y esa es la convocatoria que proponemos desde una práctica artística: armar comunidad; ir más allá de lo bello, para generar acontecimientos sociales que como resistencias se opongan a las maquinarias de poder que destruyen los procesos creativos. Ese pueblo que se arma en un acontecimiento artístico es el proceso que Deleuze llama Fabulación y que nosotros hemos adoptado como nuestro lugar de búsqueda en la relación con el arte. El concepto de fabulación (el cual fue el escenario principal de la investigación: La fabulación, acción y conceptualización en la relación arte y pedagogía 20162018), Deleuze lo retoma de Henri Bergson y lo emparenta con el de acontecimiento.

El acontecimiento del que hablamos, o sea el artístico, se da en un plano de inmanencia con un plano de composición. El campo de inmanencia es atravesado no por un concepto, como en el caso de la filosofía, sino con un acto creativo. Estos se dan en un fondo caótico, en el cual pululan una serie de virtualidades (nubes de virtualidad, que es entendida como parte de lo actual) ya que no podrían darse en un lugar del orden, sino precisamente porque irrumpen y crean una diferencia y un nuevo sentido, más allá del sentido establecido, una manera de entender el mundo y dar un punto de referencia con que pensarse otras construcciones. $O$ sea en el acontecimiento se da una multiplicidad de conexiones de diversas clases que incluso pueden ser contradictorias.

Por ese motivo pensamos que no puede hablarse del arte como un espacio de comunicación, ni de información, porque en estos ya está presente una línea de sentido que es la que mueven los sistemas dominantes. Si el acontecimiento lo que crea son vinculaciones azarosas, producción continua, devenir del devenir, se plantea como una fabulación, una fundación de un nuevo acto de habla, más allá de un suceso, porque no se sucede entre dos tiempos o como acción de una conciencia, o entre los cuerpos; al contrario el cuerpo activo es una consecuencia de los acontecimientos que operan en él. Y este se da como contrainformación que equivale a decir resistencia: 
La obra de arte no es un instrumento de comunicación. La obra de arte no tiene nada que hacer con la comunicación. La obra de arte, estrictamente, no contiene la mínima parte de información. Por el contrario, hay una afinidad fundamental entre la obra de arte y el acto de resistencia. Lo que se rompe es la binariedad del signo a la manera que lo propone Peirce; se crean nuevos sentidos (DELEUZE, 2012, p. 3).

Siguiendo a Ordoñez, entendemos que: solo por esta vía las singularidades errabundas e indóciles pueden ser agrupadas en constelaciones, organizadas en subconjuntos, dispuestas en series, ensambladas hasta dar lugar a un cierto funcionamiento, a una cierta historia; por ello es necesario el escenario del caos, ya que solamente allí en esas singularidades, el artista puede trazar un movimiento y crear una diferencia. Esto también refiere a la filosofía y a la ciencia, pero el caso que nos trae es el del arte. Decimos que el acontecimiento ocurre cuando una de estas virtualidades, por así decirlo, se libera del caos que la ciñe, se "pliega" y pasa a formar parte del conjunto de los hechos que pueblan el cosmos, del conjunto de los enunciados que pueblan el pensamiento.

Podemos decir que el acontecimiento no es exclusivamente humano (hay de todo tipo en la naturaleza). Afecta tanto el lenguaje como la naturaleza, pero su interpretación implica al ser humano. Este, puede ser de orden físico, pero el acontecimiento como verbo implica la convergencia de diferentes hechos y de ello hace parte el lenguaje. Dice Ordoñez:

Además, el acontecimiento como tal reverbera en el presente y en el pasado, porque es una problematización de eso que hemos dado como lo sentado, puesto que se establece una diferencia y un cambio en la construcción de nuestro universo simbólico y físico, porque se desbordan los límites que han establecido los poderes y así al menos en el arte, el acontecimiento se vuelve una Resistencia, una fabulación, y con ello un nuevo acto de habla. Por esta razón Deleuze afirma que en el acontecimiento no hay comunicación, porque lo que se instala es un nuevo campo de sentido, se dilatan las formas de entender, se abren otras aristas para la comprensión del mundo (2012). Estos no pueden ser objetos de análisis o de hermenéutica, sino cartográficos, topológicos. Parafraseando a Ordoñez (2011), un acontecimiento es una llovizna, un caleidoscopio que forma constelaciones que son un propio esquema y no tienen el carácter universal. Se da una variación en un plano de inmanencia, el cual es el fondo mismo en el que un acontecimiento se da. Y este fondo es la geografía, el trazar, diferente del sentido. Es decir, es el accidente, por eso se habla en Rizoma (2002) de cartografías, no de adjetivos o atributos.

En el arte, los acontecimientos son de otro orden diferente al de la filosofía, ya que no se producen por ideas, sino por bloques de sensaciones, perceptos y afectos, independiente del artista o creador, porque no es este el que los produce, ni siquiera los produce la obra misma, sino su perdurabilidad (diferente de una durabilidad temporal), la capacidad de crear actos de habla, la cualidad de conservarse en la eternidad que coexiste en la breve duración, ya que es un pedazo de tiempo eternizado; por ello el artista invita al pueblo, pero no es el protagonista del acontecimiento. Un buen artista desaparece en su obra, el yo se pierde y se crea un devenir. El movimiento abre el territorio, pero no para el artista y su ego, sino para el gesto mismo. Dice Deleuze (2011) que el territorio es el efecto del arte, no el adorno, sino el ajuste. Por ello en la 
contemporaneidad el hacer de la estética se debe instalar de otro modo diferente a lo bello, por ejemplo, desde el territorio, desde el emplazamiento de un acto de habla. Lo bello será siempre del orden del atributo, de la idea. O como dice José Luis Pardo (2001) el acontecimiento artístico, abre el cosmos, porque una práctica artística endógena asfixia, endurece, no tiene por donde respirar. Lo que quiere decir es que el hecho artístico implica no solamente la creación sino también la circulación, la oxigenación, el establecer relaciones; permanecer, no en el tiempo sino en el sentido. El arte entendido así, se despide del concepto, pues este es puramente nominal, lo cual invita a pensar en la ruptura que habrá que hacerle a la estética del arte para hablar de lo social, de lo político como el lugar de la resistencia.

Si en esta nueva lectura, el acontecimiento artístico es independiente de la obra o del artista o del espectador, porque lo que ocurre es que desborda las percepciones, entonces el arte no está ligado necesariamente con el éxito.. El acontecimiento no requiere la afluencia de gran público, sino la capacidad de convocar, de celebrar, porque el arte es celebración. Aquí aparece la potencia de la ruptura de la representación por una estética de la sensación que a su vez es creadora. Experimentar es crear y crear es resistir.

\section{Subjetivación y Fabulación}

Expone Deleuze (2015) en su curso sobre Foucault titulado La Subjetivación, que el sujeto nace en Occidente junto con la filosofía en la Antigua Grecia. La filosofía crea al sujeto en tanto elabora una nueva racionalidad para entender el mundo como algo dado, cuya naturaleza puede ser descubierta e interpretada, siendo el hombre, en específico el filósofo, la persona indicada para preguntarse por la naturaleza del ser y del mundo. Así pues, se crea un sujeto, una conciencia racional ligada a sus capacidades de pensamiento. La cosmovisión mítica y mágica sobre el mundo es desplazada por una centrada en el logos, la razón y la palabra, en la que el mundo empieza a ser ordenado y no experimentado como un caos en perpetuo retorno. La racionalidad logocéntrica crea un ser, sujeto, de características semejantes a los otros, la inteligencia entra a definirlo en su posibilidad de razonar, controlar y mantenerse fiel a una estructura de mundo. Continúa Deleuze su tesis sobre el sujeto como invención de la razón y el conocimiento con Descartes y Hegel, pensadores que reafirmarán el lugar del mundo como objeto de conocimiento frente a la racionalidad del hombre - sujeto.

En la interpretación que hace Deleuze del trabajo filosófico de Foucault, el autor logra identificar tres ejes constitutivos de su pensamiento. El primero de ellos son las formaciones de saber, el segundo las relaciones de poder y el tercero los procesos de subjetivación o de cuidado de sí; este último como lugar de pasaje, encuentro y yuxtaposición de las formaciones de saber y las relaciones de poder, o sea, el espacio en el que se pliega la fuerza sobre sí. La subjetivación como eje estético en el pensamiento de Foucault es una deriva de la forma y la fuerza, es decir, un eje autónomo, condición de posibilidad de las tácticas de resistencia. 
Deleuze, apoyado en Foucault, problematiza la conceptualización del sujeto como una construcción ontológica cuyo cimiento es necesario deconstruir, frente a los cambios biopolíticos constitutivos de las sociedades de control, descritas por Deleuze e intuidas por Foucault. De este modo, se cuestiona al sujeto en su incapacidad de deshacerse de sí mismo, de despojarse de la racionalidad logocéntrica, y de la complicidad de la inteligencia con las formas de dominación planetarias que conllevó el proceso civilizatorio occidental. Como bien explicó Foucault (1994), si la subjetividad, en tanto formación de sujetos, es un modo de sujeción, las prácticas de subjetivación o de cuidado de sí, serían las tácticas de su liberación. En este sentido, Deleuze intenta abrir el espacio ontológico del ser con la noción de Devenir, abandonar los adjetivos calificativos por verbos en infinitivo: fabular, deshacer, transitar... y de esta manera plegar la fuerza del exterior sobre sí mismo para constituir una interioridad, una subjetivación que deriva de las relaciones saber-poder que constituyen al sujeto.

La subjetivación, como el acontecimiento en que la fuerza se pliega sobre sí misma, es el proceso a través del cual se crea una interioridad, un espacio de agencia, definido en términos de Deleuze, como el adentro del afuera, es decir, el acontecimiento mismo materializado en un pliegue de subjetividad, lo que en otras palabras sería, una línea de fuga, un punto de resistencia. Pero este espacio interior no es un espacio utópico, más bien es un campo en tensión, una hibridación entre el saber, el poder y la fuerza que los pliega para derivar en otras formaciones de saber y en otras relaciones de fuerza agenciadas, paradójicamente, por el sujeto, que ya deviene subjetivaciones, un trabajo de sí sobre sí mismo.

Uno de los elementos consustanciales a la subjetivación, como acontecimiento creativo y de resistencia en el pensamiento de Deleuze (2012), es la fabulación, concepto que retoma de Henri Bergson para volver colectivo el agenciamiento de subjetividades. Devenir en manada, en contraposición a la soledad del individuo, estimular deseos colectivos, deshacerse en el otro como una forma de devenir la propia subjetividad. Fabular como alternativa a la dicotomía verdad - falsedad, convoca a la invención de un pueblo, es decir, a la integración en otras cosmogonías y mundos posibles, de ahí que el arte como acontecimiento genere un acto de habla común, solidario y carnal.

La fabulación es teorizada por Henri Bergson como una función del hombre que le permite la vida social y la creación de mundos imaginarios, esta se deriva de la inteligencia a la vez que surge como resistencia a la misma. La función fabuladora emerge de la necesidad religiosa del hombre de conectar su experiencia vital con el mundo. En sus palabras:

\footnotetext{
De hecho, la función fabuladora, que pertenece a la inteligencia y que sin embargo no es inteligencia pura, tiene precisamente este objeto. Su papel es tomado otro sentido. No tenemos, pues, más que resumir lo dicho para definir esta religión en términos precisos. Es una reacción defensiva de la naturaleza contra lo que podría haber de deprimente para el individuo, y de disolvente para la sociedad, en el ejercicio de la inteligencia (BERGSON, 1962, p. 210).
}

De acuerdo con el autor, la fabulación es la capacidad del ser humano para vivir en sociedad, es su invención noológica para crear universos de sentido que la inteligencia por sí 
sola no logra realizar, al correr el riesgo del egoísmo. En este sentido, la razón se desliga de la inteligencia al volverse social y deviene en otra función para preservar la vida:

La especie humana existe merced a que el acto mismo por el cual apareció el hombre, con su inteligencia para fabricar herramientas, con su continuo esfuerzo intelectual, y con el peligro creado por la continuación de este esfuerzo, suscitó asimismo la función fabuladora (BERGSON, 1962, p. 203).

Deleuze retoma la teorización de Bergson para darle una connotación política al concepto de fabulación, en su análisis de las sociedades de control y el poder modular constitutivo de las mismas; él argumenta que la fabulación se hace necesaria en tanto posibilidad de crear agenciamientos minoritarios, que resistan a la desmembración ontológica causada por la dominación de las mayorías, entendiendo este concepto no en sentido estadístico, si no de manera metonímica, como patrones discursivos y prácticas de dominación hegemónicas que se repiten en una sociedad. Deleuze expresa que:

Tal es la función de la fabulación bergsoniana... Sorprender a la gente en fabulación flagrante, captar el movimiento de constitución de un pueblo. Los pueblos no preexisten. En cierto modo, el pueblo es lo que falta. No hay pueblo que se constituya de otro modo (DELEUZE, 2006, p. 107).

Es claro en Deleuze el sentido social de la fabulación al hablar de la falta de un pueblo o, mejor, de múltiples pueblos, del llamado para devenir agenciamientos colectivos en un mundo fragmentado por los embates del poder. La dirección de Deleuze al hablar de la falta de un pueblo no es reformadora, es decir, no busca reintegrar la sociedad en su conjunto, al contrario, pretende ser irruptiva, al conjugarse este concepto con su pensamiento sobre el devenir y la multiplicidad, es decir, sobre la formación de devenires colectivos minoritarios, nodos de resistencia al conjunto de la sociedad que se presenta como mayoría. Como bien argumenta Antonelli:

La meta crítica de la fabulación es la ruptura de la continuidad de los relatos recibidos y las historias hegemónicas, mientras que su función positiva radica en la elaboración de imágenes liberadas de las convenciones narrativas y abiertas a la construcción de nuevos agenciamientos sociales (ANTONELLI, 2012, p. 529).

Devenir colectividades, manadas, sociabilidades es la táctica de resistencia conceptualizada por Deleuze para unir las moléculas de mundos posibles. En esta dirección, son de suma importancia para este pensador, los intercesores, esos otros con quienes se fabula y se logran actos de habla colectivos.

\section{Cartografías, heterotopías}

Nos dirigimos a los inconscientes que protestan. Buscamos aliados. Tenemos gran necesidad de aliados. Tenemos la impresión de que nuestros aliados están ya por ahí, que se nos han adelantado, que hay mucha gente que está harta, que piensan, sienten y trabajan en una dirección análoga a la nuestra: no se trata de una moda, sino de algo más profundo, una especie de atmósfera que se respira y en la que se llevan a cabo investigaciones convergentes en dominios muy diferentes (DELEUZE, 2006, p. 20). 
En la propuesta de trabajo del colectivo, nos interesa seguir el rastro de Guattari muy especialmente que vincula lo cartográfico con la producción de subjetividad. En este sentido, planteamos un tercer concepto que vincula la teoría, la práctica y la ruta cartográfica.

El término Cartografía se liga con la acción más que con la representación. Al igual que el acontecimiento y la producción de subjetividades, más allá de identificar cosas ya dadas, se sucede en la exploración y el encuentro de nuevos componentes, la creación de nuevos territorios. Es la realización de un viaje, una estrategia de orden reticular, que se establece en las construcciones de sentidos diversos, por fuera de una dirección lineal que crea una manera única de entenderse.

La cartografía responde a una tecnología de producción de lo real, pero ha estado también sometida a los escenarios de poder y saber. Entendido de esta manera, podemos pensar en que si es producción de realidad, puede remitirnos a otra posibilidad del mundo. En ese sentido, no será una representación, ya que parte de nuestra capacidad de construir realidades.

\begin{abstract}
La sustitución de la centralidad del ser (una construcción cultural, basada en la idea de esencias permanentes) por la del devenir (que sitúa el énfasis en la propia vida en su desplegarse); el posicionamiento del deseo, como composición, como performance creativa, constructiva, singularizante, como motor de los devenires, como motor de la vida; la multiplicación de las singularidades, de los deseos, de los modos de vida; la compatibilización de lo común y de lo singular, - circunstancia esta última que avanza ciertos aspectos liberadores de la sociedad red, que emerge coetánea a sus escritos, y que supone en la enunciación de Deleuze y Guattari un proyecto político crítico y nuevo (PÉREZ DE LAMA, 2009, p. 125).
\end{abstract}

La cartografía se extiende a cualquier sistema complejo, para analizar allí la presencia de elementos incluso de corte ambiguo o contradictorio, procesos sociales; equivale al mapa o al diagrama y sustituyen la idea de descripción. El diagrama para Foucault, según Deleuze es el mapa, (Matta, 2008) definido por funciones y materias informales. No hay distinción allí de "forma entre contenido y expresión, entre una formación discursiva y una no-discursiva. Es una máquina casi muda y ciega, aunque es ella la que hace ver y hablar" (DELEUZE, 2004, p. 42). Contribuye a la conexión de los campos, al desbloqueo de los cuerpos sin órganos (...) Forma parte del rizoma. Dicen Deleuze y Guattari (1998, p. 17) que el mapa es abierto a sufrir modificaciones, desmontable, puede alterarse y puede ser iniciado por un colectivo, un individuo, tiene múltiples entradas y puede ser un acontecimiento artístico, una acción o meditación.

Lo que Guattari Ilama la cartografía del deseo, respondería a los criterios nuestra propuesta, porque tiene la potencia de descentralizarse por el devenir y a partir de allí, permitiría visualizar las producciones de subjetividad, de conexiones con el inconsciente social y mostrarnos las posibilidades en las construcciones de realidades alternas a la que hemos dado por verdadera. Hacer mapa y no calco como lo proponen los autores, da lugar a devenires comunes, los cuales no pre-existen para crear acontecimientos.

Si la cartografía no pre-existe sino que siempre se está haciendo y deshaciendo de acuerdo a unas intenciones, ello quiere decir que está poblada por el deseo de una comunidad, lo que le confiere la cualidad de construirse por los intereses y de manera colectiva. Dice 
Guattari (2006) que el inconsciente es el ámbito de producción de la existencia, entonces las cartografías serían del orden de ese inconsciente colectivo producto de un deseo de resistir frente a la muerte.

Para lograr esta resistencia, una cartografía del deseo tendría que estar por fuera de los sistemas o maquinarias de control, de la representación y la copia. En este sentido para Guattari y Deleuze (2002), la cartografía es un mapa y no un calco. Esto quiere decir que siempre una cartografía se está haciendo y deshaciendo de acuerdo también a unos intereses de una comunidad. La cartografía se da como una realidad que construimos en la que queremos evidenciar algo y a través de una acción (una performance), más que de una definición, se produce este movimiento. Es claro que esta producción de deseo también necesita un campo conceptual y es ello lo que pretendemos hacer en las investigaciones que hemos realizado.

La cartografía crea un trazo, un movimiento que no reproduce los sistemas, ni siquiera los espacios fijos, precisamente porque se opone a toda fijeza. Ella construye un espacio liso, abierto, que además es modificable, desmontable y alterable. Por ello una cartografía es errancia, líneas de fuga, performances, desterritorializante y nómada (DELEUZE, 2002). Es móvil, diferente de un sistema que se cree sedentario y que se fija en una tendencia a realizar lo mismo, por siempre, muriéndose en el espacio "estriado de la representación". En cambio cartografiar es abrir, agitar, crear, experimentar y allí se dan los devenires: niños, animales, mujeres, negros, indígenas, campesinas, moleculares, imperceptibles, poéticos, musicales, pictóricos, performáticos. Es decir, los devenires de las minorías que siempre deben inventar lugares para fabular sus deseos y estos actos de fabulación se inscriben en sus cuerpos y crean actos de habla que resisten a las maquinarias lingüísticas de los poderes.

\section{Investigación-creación}

Los acontecimientos artísticos se dan a partir de un arduo trabajo, que implica no sólo la creación, sino la indagación, la búsqueda de referentes, el conocimiento de materiales, de colores, la acción de la luz sobre los objetos, el estudio del cuerpo, del movimiento, de la voz, del sonido, la atención a las coordenadas espacio-temporales, a las dimensiones, en fin; una cantidad de elementos que además implican un proceso largo de construcción, ensayos, prueba y error. Según el artista y docente de la Universidad de Antioquia Armando Montoya, el arte está fundamentado en la experiencia. Tiene la capacidad de romper esquemas, ir más allá de lo establecido como norma, vislumbrar directrices diferentes y trascender en el tiempo. Todo esto es posible gracias a la estrecha relación entre el proceso de investigación y el proceso creativo, los cuales son base para la producción artística (MONTOYA, 2006).

Para Montoya (2006), en el proceso de producción de la "obra" de arte, es la investigación la que deviene arte, pues ella da cuenta de un proceso de análisis, de interpretación, comprensión, que busca dar otros sentidos y encontrar otros significados para crear relaciones con la propia historia y con el entorno en el que incide y de esta manera transformarlo y transformarse a 
sí mismo. Por esta razón el proceso de investigación en artes no lleva una progresión lineal, ya que está supeditado a la experiencia y por tanto, es abierto a múltiples perspectivas y puntos de vista, puede tomar distintos caminos, considerar alternativas diferentes, dando lugar para lo atípico, lo paradójico, la sin salida, la contravía, posibles entrecruzamientos, giros, espirales y retornos. De acuerdo con lo anterior, entendemos el proceso de investigación como estrechamente vinculado a la acción creadora, destacando en lo dicho, el proceso y la acción, es decir, se desdibuja la concepción de "la obra de arte" como algo terminado, objeto de contemplación, distante del espectador, para transformarlo en un acontecimiento abierto a la interacción, que invita a la participación, en constante transformación y en el que cobran importancia las vivencias, los intercambios, las reflexiones que se van gestando en la experiencia. En esta medida, la investigación-creación da cuenta de un proceso que se enriquece en el día a día, en el recorrido, susceptible a los cambios y giros que puedan acontecer en el trayecto.

A pesar de esto, en muchas ocasiones estos trayectos quedan en el olvido, prevaleciendo el resultado, la obra, el fin; por eso es importante entender que precisamente en la práctica artística los procesos son parte de la construcción del saber y que es en una comunidad que tiene sentido el acontecimiento artístico.

En la investigación creación no hay una única obra, no hay un artista "dueño" de la misma, no hay un paso a paso que dirija o genere una determinada ruta, hay multiplicidades, invitaciones, propuestas, cuestionamientos, devenires; hay un llamado que congrega, involucra y vincula al investigador-creador con la vida. Con base en lo anterior, se resalta la importancia que tiene la experiencia en el proceso investigativo, pues se vuelve fundamental en tanto el mismo creador es el investigador, y en esta medida, la frontera entre campo de estudio y artista investigador se deshace para dejar emerger los relatos de los participantes. De acuerdo con esto, el arte se potencia en tanto convoca a un pueblo y permite que los bloques de afectos, sensaciones y perceptos devengan en una apuesta ética, política y estética. Entendido así, pierde su dimensión de un arte de la forma, del gusto y de lo bello y se adentra en terrenos simbólicos, mucho más comprometidos con las dinámicas ciudadanas, la cotidianidad de sus habitantes, los problemas sociales, los rituales, las formas de celebración y de duelo.

Nuestras propuestas derivadas de la investigación-creación, implican un proceso constante, móvil, cambiante, sin resultados fijos y estáticos, que nos lleva a generar obras abiertas y distintas, sin importar cuantas veces sean presentadas. Esto permite alejarnos de las concepciones y cánones establecidos en el arte occidental tradicional, ya que como se ha mencionado, no prevalece ni se tiene interés por la obra acabada y terminada, sino por los procesos que se generan durante y después de las etapas de creación. Esta dinámica permite la generación de nuevos actos de habla, de resistencia, puntos de fuga; convoca e invoca a pueblos y comunidades que no existen, que se nieguen a ser silenciadas por la opresión, el miedo y la muerte; invitan no solo a la reflexión, sino también a la celebración y reivindicación de la vida. 


\section{Más allá de una metodología}

La revolución no se juega sólo al nivel del discurso político, sino también en un plano más molecular, del lado de las mutaciones de deseo y de las mutaciones técnico-científicas, artísticas, etcétera (GUATTARI, 2015, p. 213).

Más que una metodología, proponemos una ruta cartográfica, que es según palabras de Guattari (2006), de quien tomamos este término, una invención de estrategias que nos permitirán crear un viaje. Este concepto, lo hemos propuesto en el marco teórico pero así mismo lo planteamos en la metodología, ya que no parte de un estado dado, sino por construirse siempre. Creemos que para el trabajo que hemos realizado durante estos años, la propuesta de Guattari, sirve a nuestros intereses y deseos.

La metodología tradicional se instaura como fijación de una manera de ser y de hacer; lo que pretendemos es una capacidad de deshacer y rehacer territorios, crear movimientos corporales y sociales en eso que hemos llamado fabulación o acontecimientos artísticos. En esta investigación cobran importancia lo cotidiano, el encuentro con la comunidad y sus cotidianidades, los intercambios de saberes, historias y experiencias que atraviesan la carne. A partir de allí, se propone la construcción de un conocimiento abierto a la multiplicidad, al devenir de la experiencia; que alberga la diferencia y la pluralidad como agentes potenciales del cambio y la diversidad. De este modo, presentamos nuestra ruta metodológica como una cartografía, en la que no buscamos trazar caminos definidos y predeterminados, sino recorrer trayectos susceptibles de giros, relieves y sobresaltos, abiertos a la exploración y al encuentro.

De acuerdo con lo anterior, es importante mencionar que, basados en nuestra experiencia investigativa, el camino recorrido durante los diferentes proyectos de investigación, nos permite presentar esta cartografía como una invitación al desacomodo, al riesgo, a la sospecha y al cambio; una apertura al cuestionamiento constante de nuestra propia realidad, a la indagación en los poderes que nos gobiernan y nos alienan, a la movilización de nuestros lugares de confort.

El trabajo artístico que realizamos y en general todas las apuestas creativas, siempre tendrán un ejercicio de investigación, porque no se puede hacer una creación sin crear dispositivos, relaciones, fracturas, planos conceptuales y de inmanencia; la creación es una explosión, una dispersión de afectos, perceptos y sensaciones, es una multiplicidad que se da por conexiones, formando un todo, pero como dice Guattari (2006), un todo fragmentario.

Particularmente, para atender los procesos de investigación-creación, proponemos hacer una cartografía que procede por conquista, variaciones, inyecciones, expansiones, explosiones y esto más que un modelo de intervención se vuelve una estrategia que debe ser constantemente producida porque, parafraseando a Guattari (2006), la cartografía tiene la condición de desmontable, entradas y salidas, líneas de fuga, alterable y modificable, en cuyo entramado se crean redes, más parecido a una propuesta cinematográfica que a un dibujo o un calco en un plano de consistencia o meseta en donde se crean conexiones de toda clase, 
incluso paradójicas y contradictorias. Una cartografía entonces es un trazado de un mapa de viaje, que construye espacios lisos en el que se imprimen movimientos. Una cartografía, según el autor es una performance en la que predominan la errancia y no el yo, las líneas de fuga, que es un cuerpo sin órganos desterritorializado y nómada, al contrario del calco que es sedentario, se detiene y es representativo.

En la cartografía se genera una creación a partir de la experimentación y allí se dan los devenires que son procesos de doble captura que dan como resultado un pensamiento acontecimiento (yo devengo otro, otro deviene yo) y esto rompe la representación porque se crea un salto, lo cual los diferencia de una identidad como en el teatro clásico; no se definen desde el yo, sino desde el inconsciente.

La cartografía como proceso revienta en tres escenarios: político, ético y estético y esto, según Guattari (2006), atraviesa las tres ecologías: la del medio ambiente, la relación con la naturaleza y el entorno; la ecología social, el ámbito de la vida colectiva y la ecología mental la producción de subjetividad -.

Esto nos da una manera de habitar el mundo en el que no se busca repetir y crear sujetos, sino discursividades, subjetividades. En una propuesta donde no hay un método único, sino estrategias, rutas, viajes, encuentros, sorpresas, no puede haber un sujeto que piensa, sino un sujeto que se configura y desfigura a través de los procesos, en donde se crean micro prácticas, micro movimientos, para generar otros procesos sociales a través de la creación de performatividades.

Nuestra propuesta también involucra un proyecto pedagógico y político como estrategia investigativa, que se construye en el día a día, a partir de múltiples encuentros en los que se intercambian experiencias y reflexiones. Esto implica también procedimientos que, de manera conjunta, enriquecen el proceso creativo y de investigación a través de acciones participativas que convoquen, que involucren, que hagan el llamado a un pueblo e inviten a la búsqueda de nuevas formas de hacer, diferentes a las aprendidas y normalizadas.

La investigación-creación que proponemos, hace un énfasis especial en valorar la experiencia singular y así mismo el trabajo colectivo, promoviendo la intervención social, la interacción con lo comunitario y con los actores sociales. Sin embargo, ello no excluye elementos que lo acercan a las construcciones de la investigación cualitativa, la emergencia de estrategias mixtas que permiten entrecruzar el proceso investigativo con lo vivencial, las subjetividades, lo artístico, y así mismo con lo académico y lo teórico para crear procesos que derivan en acciones y reflexiones, que para el caso del Colectivo Artístico El Cuerpo Habla, no están divididos, sino que son parte de lo mismo. 
ANTONELLI, M. El problema de la utopía en Gilles Deleuze. Isegoría: Revista de Filosofía Moral y Política, Madrid, n. 47, p. 519-539, 2012. Disponível em: http://isegoria.revistas.csic.es/index. php/isegoria/article/view/793/793. Acesso em: 15 jan. 2020. DOI: 10.3989/isegoria.2012.047.07

BADIOU, A. Lógicas de los mundos: El ser y el acontecimiento. Argentina: Bordes Manantial, 2008.

BERGSON, H. La evolución creadora. España: Aguilar, 1948.

CHAVERRA, A. El Cuerpo Habla. Tese (Doctorado em Artes). Universidad de Antioquia: Medellín, 2016. Disponível em: https://revistavirtual.ucn.edu.co/index.php/RevistaUCN/article/ view/115/227. Acesso em: 01 mar. 2020.

DELEUZE, G. ¿Qué es la filosofía?. España: Anagrama, 2001.

DELEUZE, G.; GUATTARI, F. Mil Mesetas. Capitalismo y esquizofrenia. España: Pre-textos, 2002.

DELEUZE, G. La imagen tiempo, estudios sobre cine. España: Paidós comunicación, 2004.

DELEUZE, G. Conversaciones. España: Pretextos, 2006.

DELEUZE, G. ¿Qué es el acto de creación? Revista Fermentario. Montevideo, n. 6, p. 1-16, 2012. Disponível em: http://www.fermentario.fhuce.edu.uy/index.php/fermentario/article/ view/110/70. Acesso em: 14 jan. 2020.

DELEUZE, G. La subjetivación. Curso sobre Foucault. Argentina: Cactus, 2015.

FOUCAULT, M. ¿Qué es la Ilustración? Actual. Disponível em: http://www.saber.ula.ve/ bitstream/123456789/15889/1/davila-que-es-la- ilustracion.pdf. Acesso em: 15 jan. 2020.

GUATTARI, F.; ROLNILK, S. Micropolíticas: Cartografías del deseo. España: Editora Vozes, 2005.

GUATTARI, F. ¿Que es la Ecosofía?. Argentina: Cactus, 2015.

MONTOYA, A. La investigación en arte. Cómo acceder a nuevas formas de expresión. Artes, La Revista, Medellín, v. 6, n. 12, p. 15-20, 2006. Disponível em: https://dialnet.unirioja.es/servlet/ articulo?codigo=2254847. Acesso em: 10 jan. 2020.

PARDO, J. A cualquier cosa llaman arte. Ensayo sobre los no lugares. In: LARROSA, J.; SKLIAR, C. Habitantes de Babel. Barcelona: Editorial Laertes, 2001.

PÉREZ DE LAMA, J. La práctica de la arquitectura como invención de máquinas ecosóficas.

Colegio oficial de arquitectos de Galicia, Universidad de Sevilla: España, 2009. 